\title{
The Disastrous Implications of the 'English' View of Rationality in a Social World
}

Forthcoming in Social Epistemology. DOI: 10.1080/02691728.2018.1549289

Seungbae Park

Ulsan National Institute of Science and Technology

The Republic of Korea

Email:nature@unist.ac.kr

Homepages: http://nature.unist.ac.kr, https://philpeople.org/profiles/seungbae-park

\begin{abstract}
Van Fraassen (2007, 2017) consistently uses the English view of rationality to parry criticisms from scientific realists. I assume for the sake of argument that the English view of rationality is tenable, and then argue that it has disastrous implications for van Fraassen's (1980) contextual theory of explanation, for the empiricist position that $\mathrm{T}$ is empirically adequate, and for scientific progress. If you invoke the English view of rationality to rationally disbelieve that your epistemic colleagues' theories are true, they might, in turn, invoke it to rationally disbelieve that your positive theories are true.
\end{abstract}

\section{Keywords}

Epistemic Imperative, Epistemic Reciprocalism, Golden Rule

\section{Introduction}

Suppose that $\mathrm{T}$ best explains the available data. Scientific realists and antirealists take different epistemic attitudes toward it. The literature abounds in diverse formulations of scientific realism and antirealism. This paper concerns Bas van Fraassen's (2007, 2017) position. He consistently relies on the English view of rationality to confront criticisms from David Papineau (1996) and Alan Musgrave (2017). This paper exhibits the disastrous implications of the English view of rationality for van Fraassen's (1980: Chapter 5) contextual theory of explanation, for the empiricist position that $\mathrm{T}$ is empirically adequate, and for scientific progress.

In Section 2, I explicate how van Fraassen (2007, 2017) uses the English view of rationality to counter Papineau's (1996) and Musgrave's (2017) objections. Briefly put, van Fraassen invokes the English view of rationality to disbelieve that $\mathrm{T}$ is true, and to argue that it is reasonable to believe that $\mathrm{T}$ is true. In Section 3, I elucidate the disastrous impacts that the English view of rationality has on van Fraassen's contextual theory of explanation, on the empiricist position that $\mathrm{T}$ is merely empirically adequate, and on scientific progress. Van Fraassen's critics could invoke the English view of rationality to disbelieve that the contextual theory is true and to disbelieve that $\mathrm{T}$ is empirically adequate. Scientists would not be motivated to develop new theories or experiments, if they disbelieved that their new theories are true or empirically adequate, and if they believed that their colleagues would disbelieve that the new theories are true or empirically adequate. In Section 4, I reply to several possible objections.

This paper operates under the starting point of social epistemology, namely, that we are not asocial epistemic agents but rather social epistemic agents (Goldman, 1999: 4). Social epistemic agents "take into account how their interlocutors treat their epistemic colleagues before taking epistemic attitudes towards their interlocutors' positive theories" (Park, 2018a: 
37). From this perspective, I argue that if social epistemic agents invoke the English view of rationality in order to disbelieve that their interlocutors' theories are true, they will face an epistemic backlash against their own positive theories.

\section{Van Fraassen's Defense}

According to van Fraassen, scientific realism asserts that "acceptance of a scientific theory involves the belief that it is true" (1980: 8). By contrast, constructive empiricism asserts that "acceptance of a theory involves as belief only that it is empirically adequate" (1980: 12). Note that scientific realism and constructive empiricism are formulated in terms of acceptance, and that they are silent about whether it is reasonable to believe that $\mathrm{T}$ is true or empirically adequate.

Van Fraassen says consistently, "I do not advocate agnosticism about the unobservable, but claim that belief is supererogatory as far as science is concerned; you may if you like, but there is no need" (2007: 343, 2017: 99). How can van Fraassen say that it is reasonable to believe that $\mathrm{T}$ is true, when he is widely regarded as an antirealist in the literature? The answer lies in the English view of rationality, which van Fraassen (1989: 171-172) favors over the Prussian view of rationality. Thus, we need to be clear about what these views of rationality assert.

According to the English view of rationality, "what it is rational to believe includes anything that one is not rationally compelled to disbelieve"; by contrast, according to the Prussian view, "what it is rational to believe is exactly what one is rationally compelled to believe" (van Fraassen, 1989: 171-172). The English and Prussian views of rationality are analogous to the English and Prussian legal systems. According to the former, "everything is permitted that is not explicitly forbidden," but according to the latter, "everything is forbidden which is not explicitly permitted" (van Fraassen, 1989: 171).

As the English legal system is more tolerant of human behaviors than the Prussian legal system, so the English view of rationality is more tolerant of beliefs than the Prussian view of rationality. Under the English view of rationality, it is reasonable to believe that $\mathrm{T}$ is true unless there is a compelling reason to disbelieve that it is true. What if there is a compelling reason to disbelieve that $\mathrm{T}$ is true? Then it is reasonable to disbelieve that $\mathrm{T}$ is true, and unreasonable to believe that $\mathrm{T}$ is true. In contrast, under the Prussian view of rationality it is reasonable to believe that $\mathrm{T}$ is true if and only if there is a compelling reason to believe that it is true. What if there is no compelling reason to believe that $\mathrm{T}$ is true? Then it is reasonable to disbelieve that $\mathrm{T}$ is true and unreasonable to believe that $\mathrm{T}$ is true.

In addition to adopting the English view of rationality over the Prussian view of rationality, van Fraassen thinks that there is no compelling reason to believe that $\mathrm{T}$ is true on the grounds that it is a product of inference to the best explanation (IBE), which he does not take to be reliable. An interesting question arises: What beliefs would he take to be reasonable or unreasonable under the English view of rationality? Answering this question requires that we investigate what beliefs are reasonable or unreasonable under the English and Prussian views of rationality, respectively, and under the respective assumptions that IBE is compelling and not compelling.

What beliefs are reasonable under both the English view of rationality and the assumption that IBE is compelling? There is a compelling reason to believe that T is true, so it is reasonable to believe that $\mathrm{T}$ is true, but unreasonable to disbelieve that $\mathrm{T}$ is true. In other words, under the condition that IBE is compelling, the English view of rationality is tolerant of the belief of T, but intolerant of the disbelief of T. So epistemic agents ought to choose the belief of $\mathrm{T}$ over the disbelief of $\mathrm{T}$. 
How about under the English view of rationality and the assumption that IBE is not compelling? There is no compelling reason to believe that $\mathrm{T}$ is true, so it is reasonable to disbelieve that $\mathrm{T}$ is true. There is, however, also no compelling reason to disbelieve that $\mathrm{T}$ is true, so it is reasonable to believe that $\mathrm{T}$ is true. In other words, when IBE is not compelling, the English view of rationality is tolerant of both the belief of $\mathrm{T}$ and the disbelief of $\mathrm{T}$. As a result, epistemic agents are free to choose either the belief of $\mathrm{T}$ or the disbelief of $\mathrm{T}$. Van Fraassen holds this position.

How about under the Prussian view of rationality and the assumption that IBE is compelling? There is a compelling reason to believe that $\mathrm{T}$ is true, so it is reasonable to believe that $\mathrm{T}$ is true, but unreasonable to disbelieve that $\mathrm{T}$ is true. In other words, under the assumption that IBE is compelling, the Prussian view of rationality is just like the English view of rationality: it is tolerant of the belief of $\mathrm{T}$, but intolerant of the disbelief of $\mathrm{T}$. So epistemic agents ought to choose the belief of T over the disbelief of $\mathrm{T}$.

How about under the Prussian view of rationality and the assumption that IBE is not compelling? There is no compelling reason to believe that $\mathrm{T}$ is true, so it is unreasonable to believe that $\mathrm{T}$ is true, and reasonable to disbelieve that $\mathrm{T}$ is true. In other words, under the assumption that IBE is not compelling, the Prussian view of rationality is intolerant of the belief of $\mathrm{T}$ and tolerant of the disbelief of $\mathrm{T}$. So epistemic agents ought to choose the disbelief of $\mathrm{T}$ over the belief of $\mathrm{T}$.

What difference do the two views of rationality make concerning the issue of whether it is reasonable to believe that $\mathrm{T}$ is true? As we have just seen, the answer depends on whether IBE is compelling. If IBE is compelling, both views hold that it is reasonable to believe that T is true and unreasonable to disbelieve that $\mathrm{T}$ is true. What if IBE is not compelling? Under the English view of rationality, it is reasonable either to believe or to disbelieve that $\mathrm{T}$ is true. Under the Prussian view of rationality, however, it is unreasonable to believe that $\mathrm{T}$ is true, and reasonable to disbelieve that $\mathrm{T}$ is true. Thus, if IBE is not compelling, it would be reasonable or unreasonable to believe that $\mathrm{T}$ is true, depending on which of the two views of rationality is tenable.

Van Fraassen believes that IBE is not compelling, so it initially appears that he is agnostic about unobservables as well as that he does not take it to be reasonable to believe that $\mathrm{T}$ is true. He, however, invokes the English view of rationality to argue that it is reasonable to believe that $\mathrm{T}$ is true. ${ }^{1}$ Recall that the English view of rationality tolerates the belief that $\mathrm{T}$ is true in the absence of a compelling reason to disbelieve that $\mathrm{T}$ is true. Thus, the English view of rationality has made van Fraassen's position sophisticated and resistant to Papineau's and Musgrave's criticisms, to which I turn now.

Papineau says, “According to van Fraassen's 'constructive empiricism' ... we ought never to believe in the truth of any theory which goes beyond the observable phenomena" (1996: 8). Van Fraassen replies, "That 'ought' may be true of some conceivable empiricist philosophy of science, but I don't know of any actually professed, and it is certainly not true of constructive empiricism" (2017: 99). Thus, Papineau's criticism against constructive empiricism misfires. Musgrave contends that "it is reasonable to believe that $\mathrm{H}$ is true" (2017: 80). Van Fraassen retorts that "such a belief is reasonable enough, but supererogatory" (2017: 102). Thus, Musgrave's criticism does not refute van Fraassen's position. Note that van

\footnotetext{
${ }^{1}$ Is van Fraassen justified in believing that the English view of rationality is tenable? Park (2017a: 26-27) argues that van Fraassen should first show, before embracing the English view of rationality, that it is better than the Prussian view of rationality, and that a tenable view of rationality is more likely to lie in the set of conceived views of rationality than in the set of unconceived views of rationality. In other words, Park puts the English view of rationality into the gauntlet of van Fraassen's (1989: 143) argument from a bad lot.
} 
Fraassen appeals to the English view of rationality to argue that it is reasonable to believe that $\mathrm{T}$ is true.

In addition, van Fraassen claims that the refutation of his position requires not the proof that it is reasonable to believe that $\mathrm{H}$ is true, but the proof that "it is unreasonable not to believe that $\mathrm{H}$ is true" (2017: 102). This claim is not surprising, given that under the English view of rationality, it is reasonable either to believe or disbelieve that $\mathrm{T}$ is true. The way to refute that it is reasonable to disbelieve that $\mathrm{T}$ is true is to prove that it is unreasonable to disbelieve that $\mathrm{T}$ is true. How can we prove that it is unreasonable to disbelieve that $\mathrm{T}$ is true? The only way to do it is to prove that IBE is compelling. It is of no use to appeal to the English view of rationality or the Prussian view of rationality. As we have seen, if IBE is compelling, it is unreasonable to disbelieve that $\mathrm{T}$ is true under both the English and Prussian views of rationality, and if IBE is not compelling, it is reasonable to disbelieve that $\mathrm{T}$ is true under both.

It is beyond the scope of this paper to prove that IBE is compelling. This paper rather assumes for the sake of argument that IBE is epistemically impotent, and that the English view of rationality is tenable, and then exposes disastrous corollaries that van Fraassen would find unacceptable. One of those corollaries concerns van Fraassen's (1980: Chapter 5) contextual theory of explanation, to which I now turn.

\section{Disastrous Implications}

\subsection{The Contextual Theory of Explanation}

According to van Fraassen's (1980: Chapter 5) contextual theory of explanation, an explanation answers a why-question, and the explanation is legitimate or illegitimate, depending on what the interests of explainers and explainees are, and what the contrast class is. Van Fraassen (1980: Chapter 5) uses IBE, as Park (2017b: 61-62, 2018b: 441) observes, to argue that the contextual theory is true. Van Fraassen (1980: 112) proposes that the true theory of explanation should explain rejections and asymmetries in science. He then argues that these phenomena in science can be explained by the contextual theory, but not by the rival theories proposed by Carl Hempel (1966), Wesley Salmon (1971), and Michael Friedman (1974). In short, he claims that his theory is true on the grounds that it explains rejections and asymmetries.

How might critics react to the contextual theory? They might appeal to the English view of rationality and the epistemic impotence of IBE, saying that it is reasonable to disbelieve that the contextual theory is true. They might add that they disbelieve that it is true, that it is reasonable, even for contextualists, to disbelieve that the contextual theory is true, and that the refutation of their position requires not proof that it is reasonable to believe that the contextual theory is true, but rather proof that it is unreasonable to disbelieve that the contextual theory is true. The critics have embraced a view called epistemic reciprocalism, according to which "we ought to treat our epistemic colleagues, as they treat their epistemic colleagues" (Park, 2017b: 57).

Contextualists might reply that philosophy differs from science, so the English view of rationality applies to science, but not to philosophy. $\mathrm{T}$ is a scientific theory best explaining phenomena that occur in the world, whereas the contextual theory is a philosophical theory best explaining rejections and asymmetries that occur in science. Consequently, it is reasonable to disbelieve that $\mathrm{T}$ is true, but unreasonable to disbelieve that the contextual theory is true.

Such a reply, however, is self-serving. It would only invite an equally self-serving response from scientists, namely, that it is reasonable to disbelieve that the contextual theory is true but unreasonable to disbelieve that $\mathrm{T}$ is true. Scientists might add that they believe that 
$\mathrm{T}$ is true, and disbelieve that the contextual theory is true. Furthermore, they might argue that the refutation of their position requires not proof that it is reasonable to believe that the contextual theory is true and disbelieve that $\mathrm{T}$ is true but instead proof that it is unreasonable to disbelieve that the contextual theory is true and believe that $\mathrm{T}$ is true. They would try to justify their differing treatments of $\mathrm{T}$ and the contextual theory by saying that $\mathrm{T}$ explains natural phenomena, whereas the contextual theory explains scientific phenomena. Blunt scientists might add that it displays arrogance for philosophers to contend that a scientific theory falls prey to the epistemic impotence of IBE and the English view of rationality, but that a philosophical theory does not.

This imaginary exchange between contextualists and scientists ${ }^{2}$ highlights a philosophical moral: If one plans to advance a positive theory, one might as well refrain from rejecting IBE and wielding the English view of rationality against the theories of one's epistemic colleagues. Indeed, one's epistemic colleagues might, in return, reject IBE and wield the English view of rationality against one's positive theory, saying that it is reasonable to disbelieve that it is true, that they disbelieve that it is true, and that the refutation of their position requires not proof that it is reasonable to believe that one's positive theory is true, but rather proof that it is unreasonable to disbelieve that one's positive theory is true. They might go further, saying that it would be reasonable even for the author of a positive theory to disbelieve that it is true. Hence, it is entirely possible that no one believes that it is true, and one cannot accuse anyone of being irrational.

What is wrong with a situation in which no one believes that our positive theories are true? We have the epistemic goal "to propagate to others our own theories which we are confident about" (Park, 2017b: 58). We tend to feel depressed if we fail to achieve this epistemic goal. To reject IBE and accept the English view of rationality is an effective means to kick the epistemic goal away from us.

This disastrous implication of the English view of rationality for the contextual theory of explanation reminds us of the epistemic imperative: "Act only on an epistemic maxim through which you can at the same time will that it should become a universal one" (Park, 2018b: 441). If contextualists cannot universalize the epistemic maxim "Apply the English view of rationality to one's interlocutors' theories," they ought not to act on that epistemic maxim with respect to scientists' theories. On the matter of what to believe and disbelieve, contextualists ought to treat scientists as they want to be treated by scientists. Specifically, if they do not want scientists to use the English view of rationality to disbelieve that the contextual theory is true, they ought not to use it to disbelieve that scientific theories are true. After all, there "is no reason for thinking that the Golden Rule ranges over moral matters, but not over epistemic matters" (Park, 2018c: 77-78).

\subsection{Empirical Adequacy}

In the previous section, I argued that the epistemic impotence of IBE and the English view of rationality has a negative impact on the contextual theory. In this section, I argue that the same thing happens to the empiricist position that $\mathrm{T}$ is merely empirically adequate.

The epistemic impotence of IBE and the English view of rationality, taken together, imply that it is reasonable to disbelieve that $\mathrm{T}$ is true. What can disbelievers of $\mathrm{T}$ believe with respect to $\mathrm{T}$ ? They can believe that $\mathrm{T}$ is approximately true, that $\mathrm{T}$ is empirically adequate, that $\mathrm{T}$ is approximately empirically adequate, ${ }^{3}$ and that some observational consequences of $\mathrm{T}$ are true. Van Fraassen (1985: 294) chooses the belief that $\mathrm{T}$ is empirically adequate,

\footnotetext{
2 See Park (2018b: 440, 2018d: 16-17) for other similar confrontations between antirealists and scientists.

$3 \mathrm{~T}$ is approximately empirically adequate if and only if "most of its observational consequences are true" (Park, 2009: 117 , footnote).
} 
appealing to the principle of economy. His idea is that truth entails empirical adequacy, but not vice versa, so the realist belief that $\mathrm{T}$ is true is more likely to be false than the empiricist belief that $\mathrm{T}$ is merely empirically adequate. It follows that you should choose the latter over the former, although both are reasonable.

A problem with appealing to the principle of economy, however, is that there is an even more economical position: skepticism. 'Skepticism' here is defined as the view that some observational consequences of $\mathrm{T}$ are true. Skeptics admit that it is reasonable to believe that $\mathrm{T}$ is empirically adequate, but add that it is also reasonable to disbelieve that it is empirically adequate, that they disbelieve that $\mathrm{T}$ is empirically adequate, that they merely believe that some observational consequences of $\mathrm{T}$ are true, and that the refutation of their position requires not proof that it is reasonable to believe that $\mathrm{T}$ is empirically adequate, but rather proof that it is unreasonable to disbelieve that $\mathrm{T}$ is empirically adequate. Skeptics take less epistemic risk than empiricists, just as empiricists take less epistemic risk than realists; thus, skeptics are gadflies to empiricists, just as empiricists are gadflies to realists. Suppose that empiricists-cum-scientists have worked day and night for several years to obtain experimental data agreeing with $\mathrm{T}$. They finally obtain such data. They are so excited about their accomplishment that they make a case for $\mathrm{T}$ at a scientific conference, declaring that it is reasonable to believe that $\mathrm{T}$ is empirically adequate. To their dismay, however, their epistemic colleagues, skeptics, disbelieve that $\mathrm{T}$ is empirically adequate. The empiricists emphasize that since $\mathrm{T}$ best explains phenomena, it is reasonable to believe that $\mathrm{T}$ is empirically adequate. Skeptics admit that it is reasonable to believe that $\mathrm{T}$ is empirically adequate, but add that it is also reasonable to disbelieve that $\mathrm{T}$ is empirically adequate. Moreover, they state that it is supererogatory to believe that $\mathrm{T}$ is empirically adequate, so they disbelieve that $\mathrm{T}$ is empirically adequate. They have rejected IBE, and then accepted both the English view of rationality and the principle of economy! The empiricists cannot accuse the skeptics of being irrational.

This epistemic quagmire that the empiricists are in can lead to a practical quagmire. Imagine that the empiricists apply for a scholarly prize (Park, 2018e: 10-11). They argue to the award committee that since their scientific theory best explains available data, it is reasonable to believe that it is empirically adequate. To their disappointment, however, the committee dismisses their application, saying that the committee disbelieves that their scientific theory is empirically adequate, and that the committee has a policy according to which granting an award to the author of $\mathrm{T}$ requires that the committee believes that $\mathrm{T}$ is empirically adequate. The committee admits that it is reasonable to believe that the empiricists' scientific theory is empirically adequate, but adds that it is also reasonable to disbelieve that it is empirically adequate, and that the committee disbelieves that it is empirically adequate. The committee has rejected IBE, and then accepted both the English view of rationality and the principle of economy! The empiricists cannot accuse the committee of being irrational.

What if the committee sets aside the principle of economy? The committee can avail itself of any of three competing beliefs, namely, that $\mathrm{T}$ is true, that $\mathrm{T}$ is merely empirically adequate, and that some observational consequences of $\mathrm{T}$ are true. Which belief should the committee choose? The English view of rationality does not have an answer to this question, having no theoretical resource to rank competing rational options. So the committee can rationally choose any of them. Thus, the committee can determine on a whim whether the empiricists will receive the scholarly award.

This imaginary story about the award committee suggests that the English view of rationality would have a harmful effect on scientific progress if science policymakers used it in deciding how to distribute incentives to competing scientists. Scientific progress can be 
best achieved when the incentives are distributed fairly and predictably, but not when they are distributed whimsically and unpredictably. The fair and predictable distribution of incentives, however, falls under the axe of the English view of rationality.

There is another reason to think that the English view of rationality might have a negative impact on scientific progress. Scientists are motivated to entertain new theories and experiments, if they believe that their new theories are true or empirically adequate, and if they believe that their colleagues would also believe that their new theories are true or empirically adequate. By contrast, they are discouraged from ideating new theories and experiments, if they disbelieve that their new theories are true or empirically adequate, or if they believe that their colleagues would disbelieve that the new theories are true or empirically adequate. It follows that "realism encourages scientists to be creative, whereas pessimism discourages them from being creative" (Park, 2016: 122). The belief that T is true or empirically adequate is an incentive for scientists to develop $\mathrm{T}$ and experiments for it, whereas the disbelief that $\mathrm{T}$ is true or empirically adequate is a disincentive. The English view of rationality, however, allows for the disbelief that $\mathrm{T}$ is true or empirically adequate. Therefore, it has the potential to have a negative impact on scientific progress.

Van Fraassen has raised the scientific realism debate to a more sophisticated level by introducing the English view of rationality into it. As a historian of science observes, however, "recognition of originality is a crucial aspect and driving force in the progress of science" (Seeman, 2018: 1). Scientists' original ideas may be dismissed if their colleagues embrace the English view of rationality and, as a result, rationally embrace skepticism about the original ideas. As far as I can tell, the English view of rationality is merely a philosophical toy. It is concocted solely for van Fraassen's philosophical purpose of fortifying his position that it is reasonable to disbelieve that $\mathrm{T}$ is true. It cannot be seriously put to use in the context of taking an epistemic attitude toward real scientists' theories. Philosophers who still take it to be a feasible theory of rationality would have to reflect upon its disastrous consequences for their positive philosophical theories.

In this section, I elucidated disastrous implications of the English view of rationality. In the next section, I explore some possible criticisms.

\section{Objections and Replies}

\subsection{Concerning the Contextual Theory}

In Section 3.1, I claimed that van Fraassen argues that his theory of explanation is true on the grounds that it explains rejections and asymmetries. Critics might object that he can be interpreted as claiming not that the contextual theory is true, but instead that it is empirically adequate or better than its rival theories of explanation. Van Fraassen states as follows:

To be successful, a theory of explanation must accommodate, and account for, both rejections and asymmetries. I shall now examine some attempts to come to terms with these, and gather from them the clues to the correct account. (van Fraassen, 1980: 112)

There is no claim here that this account is true, only that it is successful and correct. Why would van Fraassen not interpret these words as synonyms for empirical adequacy? Nor is there any evidence that van Fraassen assumes that his account of explanation is the best; it is simply better than the accounts of explanation proffered by Hempel, Salmon, and Friedman in covering rejections and asymmetries. So it is possible that among this small set of competitors, it is the only one that is empirically adequate, and it is also possible that there is a true theory of explanation that is better than the contextual theory, but that constructive empiricists are under no compulsion to accept this true theory. It is hard to see how my 
argument hits its target on this interpretation, which seems to be more charitable to van Fraassen's position than my interpretation is. ${ }^{4}$

The foregoing defense of van Fraassen's position is a standard one. It is customary for philosophers to defend a target philosopher's position by saying that the target philosopher's position is closer to skepticism than critics think. There are, however, a few reasons for thinking that this standard defense of van Fraassen's position, although admirable, is mistaken.

First, by 'correct,' van Fraassen means not empirically adequate but true. If he meant empirically adequate, he would use 'empirically adequate' instead of 'correct.' After all, 'empirical adequacy' is a technical term, and writers seldom use a synonym in place of a technical term for the stylistic purpose of using diverse expressions. Moreover, contrary to what the standard defense suggests, van Fraassen's writing indicates that he believes that the contextual theory is true. He explicitly states, "An explanation is an answer to a why-question" (1980: 134), and "among the scientifically relevant factors, context determines explanatorily relevant ones" (1980: 126). If he merely believed that the contextual theory is empirically adequate, he would not say such sentences, and he would rather say that the explananda of the contextual theory, such as rejections and asymmetries, occur in science, i.e., he would rather say "that explanatory phenomena occur in science" (Park, 2017a: 28). If he merely believed that the contextual theory is better than its competitors, he could not say that an explanation answers a why-question, and he could not even say that it is empirically adequate, and hence he could not even say that the explanatory phenomena occur in science.

Second, van Fraassen would not give up the position that the contextual theory is true, given that the English view of rationality implies that it is reasonable to believe that the contextual theory is true. Moreover, we tend to be generous to our own theories and tend to be harsh on others' theories, i.e., we tend to be confident that our own theories are true, and tend to be skeptical that our epistemic colleagues' theories are true. So it is unlikely that van Fraassen would merely believe that his own theory, the contextual theory, is empirically adequate or better than its rivals, although he does not believe that his epistemic colleagues' theories are true.

Third, recall that according to the standard defense, it is hard to see how my argument hits its target. I, however, have never claimed that it is unreasonable to believe that the contextual theory is true. I have rather claimed that it is reasonable to disbelieve that it is true. Thus, the standard defense involves a mistake similar to that of Papineau (1996) and Musgrave (2017). Papineau and Musgrave mistakenly believe that according to van Fraassen, it is unreasonable to believe that $\mathrm{T}$ is true, and they then argue that it is reasonable to believe that $\mathrm{T}$ is true. Analogously, the standard defense erroneously suggests that according to the present paper, it is unreasonable to believe that the contextual theory is true, and then suggests that van Fraassen can be interpreted as merely believing that the contextual theory is empirically adequate or better than its competitors.

Let me turn to another possible objection from my critics. There seems to be widespread agreement among theorists of explanation that van Fraassen's account of explanation imposes necessary conditions on explanation. (Very roughly, every explanation stands in a relevance relation to its contrast class.) The criticisms appear to be targeted at its insufficiency (e.g., Kitcher and Salmon). But if this is correct, then critics of van Fraassen's theory of explanation cannot disbelieve it, though van Fraassen can disbelieve any consequences of a rival theory of explanation that are not consequences of his contextual theory. Hence, everything that is compelling to constructive empiricists about explanation is

\footnotetext{
${ }^{4}$ I thank the first anonymous referee for this objection.
} 
compelling to realists, but not vice versa. So absent further elaboration, my reciprocity argument against the contextual theory is not entirely convincing. ${ }^{5}$

We can grant for the sake of argument that the contextual theory is better than its competitors, or even that all theorists of explanation agree that the contextual theory is the best. An interesting question is whether we should believe that it is true. In my view, we do not need to, given that it is a product of IBE, and given that the English view of rationality implies that it is reasonable to disbelieve that it is true. This epistemic attitude toward the contextual theory mirrors van Fraassen's epistemic attitude toward T.

Moreover, this possible objection and the standard defense sketched above involve a double standard to constructive empiricists and their critics with respect to theories of explanation. The standard defense states that "there is a true theory of explanation that is better than the contextual theory, but that constructive empiricists are under no compulsion to accept this true theory." The present possible objection, however, states that "critics of van Fraassen's theory of explanation cannot disbelieve it." Note that according to these two possible objections, constructive empiricists are under no compulsion to accept the true theory, whereas their critics are under a compulsion to accept the contextual theory. In my view, given that both the true theory and the contextual theory are products of IBE, both constructive empiricists and their critics are under no compulsion to accept either of the two theories. Hence, the critics are free to disbelieve the contextual theory.

Let me turn to another possible objection. Even if my reciprocity arguments against van Fraassen's position go through, it is not clear why this would be problematic to a proponent of the English view of rationality. Some people reasonably believe that explanations are contextual; others reasonably disbelieve that explanations are contextual. The latter will presumably opt for a different theory of explanation. All of this seems quite congenial to the English view of rationality. ${ }^{6}$

It is a sharp observation that the English view of rationality can divide philosophers of explanation into two opposing groups with respect to the contextual theory. This observation, however, is compatible with my previous contention that on the English view of rationality, it is reasonable to disbelieve that the contextual theory is true, and hence it is entirely possible that no one believes that it is true, and that contextualists cannot accuse anyone of being irrational. Imagine that van Fraassen disbelieves that epistemic reciprocalists' positive theories are true, that he advances the contextual theory, and that he says to them, "You may reasonably disbelieve my contextual theory and reasonably believe its competitor." Epistemic reciprocalists would be happy to say, "Of course! I disbelieve your theory, since you disbelieve my theory." It follows that van Fraassen and epistemic reciprocalists would go their own ways without attempting to achieve the epistemic goal of propagating the truth of their theories to their epistemic colleagues.

\subsection{Concerning the Award Committee}

In Section 3.2, I claimed that the award committee has the policy that granting an award to the author of $\mathrm{T}$ requires that the committee believe that $\mathrm{T}$ is empirically adequate. My opponents, however, might object that it is not clear what the grounds for this policy are. ${ }^{7}$

An answer to this interesting objection can be found in the English view of rationality, which implies that it is reasonable for the committee to believe that $\mathrm{T}$ is true, that it is empirically adequate, and that some of its observational consequences are true. Corresponding to these three epistemic options are the three pragmatic options or the three

\footnotetext{
5 I thank the first anonymous referee for this objection.

${ }^{6}$ I thank the first anonymous referee for this objection.

7 I thank the second anonymous referee for this objection.
} 
award-granting policies, viz., granting an award to the author of T requires that the committee believe that $\mathrm{T}$ is true, that $\mathrm{T}$ is empirically adequate, and that some observational consequence of $\mathrm{T}$ are true. Just as the three epistemic options are all reasonable, so the three policies are all reasonable. So the committee is free to choose the second policy, and the empiricists cannot accuse the committee of being irrational. Van Fraassen should not have a problem with the committee's making the three pragmatic options parallel to the three epistemic options. After all, he modeled the English view of rationality and the Prussian view of rationality on the English legal system and the Prussian legal system, as we have already seen in Section 2, which indicates that he believes that epistemic and pragmatic concerns can go hand in hand.

Let me turn to another possible objection concerning the award committee. I claimed that the committee would determine on a whim whether the empiricists receive the prize. Critics might object that this claim is not convincing. The committee would have no epistemic reason for choosing a realist, a constructive empiricist, or a skeptical proposal. But this does not preclude pragmatic reasons from tipping the scale. Moreover, this seems quite congenial to virtually the entirety of van Fraassen's corpus. Parallel points apply to the closing remark about creativity and scientific motivation.

This objection, however, ironically goes well with my previous contention that the epistemic disadvantage of disbelieving $\mathrm{T}$ might be "accompanied by enormous practical disadvantages" (Park, 2018e: 10). Admittedly, the pragmatic reasons might tip the scale. An interesting question is in whose favor the scale would tip. The scale might not tip in the empiricists' favor. The empiricists merely believe that the committee members' theories are empirically adequate. The committee members can rationally and merely believe that the empiricists' proffered theory is empirically adequate, and they can rationally adopt the policy that they believe that $\mathrm{T}$ is true in order to grant an award to the author of $\mathrm{T}$, thereby rationally rejecting the empiricists' application for the award. Thus, the empiricists might suffer from practical disadvantages due to the English view of rationality.

My opponents might object that it is unlikely that an award committee would ever use the philosophical criteria to decide on a prize for scientists, i.e., it is unlikely that such a committee exists. ${ }^{8}$

My response to this objection is to point out that the philosophical criteria are reasonable under the English view of rationality. I made up the story of the award committee to make the philosophical point that the English view of rationality has disastrous implications, i.e., that it can bring practical disadvantages that van Fraassen would found unacceptable. Making the philosophical point does not require that such a committee exists. If readers feel that such a committed does not exist, I achieved the aim that I intended to achieve with the story of the award committee.

\subsection{Concerning Skepticism}

In Section 3.2, I claimed that skeptics are gadflies to empiricists, just as empiricists are gadflies to realists. Objectors might point out that given that the gadfly relationship is transitive, skeptics are also gadflies to realists. So it is not quite clear what the upshot of my argument is. $^{9}$

It is a keen observation that skeptics are also gadflies to realists. This observation, however, is compatible with my previous argument. The upshot of my previous argument is that just as van Fraassen invokes the principle of economy to disbelieve that $\mathrm{T}$ is true and to argue that it is supererogatory to believe that $\mathrm{T}$ is true, so skeptics invoke the principle of

\footnotetext{
${ }^{8}$ I thank the first anonymous referee for raising this issue.

${ }^{9}$ I thank the first anonymous referee for this criticism.
} 
economy to disbelieve that it is empirically adequate and to argue that it is supererogatory to believe that $\mathrm{T}$ is empirically adequate. If realists have the burden of showing that it is not supererogatory to believe that $\mathrm{T}$ is true, empiricists also have the burden of showing that it is not supererogatory to believe that $\mathrm{T}$ is empirically adequate. Gadflies are burden-generators for both realists and empiricists.

Let me turn to another possible objection regarding skepticism. Why should constructive empiricists who endorse the English conception of rationality be bothered by skepticism? Why would skepticism not just be another option along with realism and constructive empiricism? ${ }^{10}$

This question is pertinent, though it cannot be answered at length in this paper. The suggestion that skepticism is a viable option would be rejected by some philosophers, including van Fraassen. They say, "Skepticism is an ugly threat; a philosophical position which leads to skepticism reduces itself to absurdity" (Ladyman, Douven, Horsten, and van Fraassen, 1997: 317). These philosophers do not present any argument for this view about skepticism. In my view, skepticism is absurd because it comes with the following price tags.

First, if you are skeptical about T, you should also be skeptical about your own theories. It is a double standard for you to be confident about your own theories but skeptical about others' theories (Park, 2017b: 61). Relatedly, if you are skeptical about T, epistemic reciprocalists would be skeptical about your theories (Park, 2017b: 62). It follows that to embrace skepticism is to kick away the epistemic goal to spread the truth of your theories to your epistemic colleagues (Park, 2017b: 58). As pointed out earlier in Section 4.2, this epistemic disadvantage might incur practical disadvantages, e.g., the denial of a scholarly reward.

Second, if you are skeptical about a theory, philosophical or scientific, you cannot use it to explain phenomena due to Moore's paradox (Park, 2017c: 383, 2018a: 33-34). In certain social contexts, your speech acts might even be puzzling and unethical (Park, 2014: 342, 2015: 227, 2017b: 60, 2018a: 32-33). Relatedly, if you are skeptical about a theory, philosophical or scientific, you cannot understand phenomena in terms of the theory (Park, 2017c: 381-386, 2017d: 572-573). All these provocative views about the nature of scientific explanation and the nature of scientific understanding are defended at length in the cited papers.

\section{Conclusion}

Van Fraassen believes that IBE is not compelling. He invokes the English view of rationality to argue that it is reasonable to believe that $\mathrm{T}$ is true. This move effectively nullifies the criticisms from Papineau (1996) and Musgrave (2017), who argue that it is reasonable to believe that $\mathrm{T}$ is true. Yet, van Fraassen disbelieves that $\mathrm{T}$ is true, and claims that it is rational for him to do so.

In response, I argued that the epistemic impotence of IBE and the English view of rationality, taken together, imply that it is reasonable to disbelieve that van Fraassen's contextual theory is true and to disbelieve that $\mathrm{T}$ is empirically adequate. Critics of the contextual theory disbelieve that the contextual theory is true, and contend that the refutation of their position requires not proof that it is reasonable to believe that the contextual theory is true, but rather proof that it is unreasonable to disbelieve that $\mathrm{T}$ is true. Skeptics of $\mathrm{T}$ disbelieve that $\mathrm{T}$ is empirically adequate, and contend that the refutation of their position requires not proof that it is reasonable to believe that $\mathrm{T}$ is empirically adequate, but instead proof that it is unreasonable to disbelieve that $\mathrm{T}$ is empirically adequate.

${ }^{10}$ I thank the first anonymous referee for this question. 
The disbelief that $\mathrm{T}$ is empirically adequate brings about both epistemic and practical disadvantages to empiricists. The epistemic disadvantage is that empiricists' colleagues might, in return, disbelieve that empiricists' theories are empirically adequate. The practical disadvantage is that they might not provide empiricists with incentives. Moreover, scientists would not be motivated to develop new theories and experiments, if they disbelieve that their new theories are true or empirically adequate, and if they believe that their epistemic colleagues would disbelieve that their new theories are true or empirically adequate. Therefore, the English view of rationality has the potential to hamper scientific progress.

The disastrous impact of the English view of rationality does not stop at the contextual theory and the empiricist position that $\mathrm{T}$ is empirically adequate. ${ }^{11}$ It extends to other positive philosophical proposals, including P. Kyle Stanford's (2000) antirealist explanation of the success of science, which holds that a theory is successful because it is predictively similar to a true theory. On Stanford's account, the hypothesis that the Ptolemaic theory is predictively similar to the Copernican theory explains why the Ptolemaic theory was successful. Suppose for the sake of argument that Stanford's hypothesis best explains the success of science. ${ }^{12}$ The English view of rationality, however, implies that it is reasonable to disbelieve that Stanford's hypothesis is true. Interested readers may apply the English view of rationality to other positive philosophical proposals, such as K. Brad Wray's (2007, 2010) selectionist explanation of the success of science.

Let me end this paper with a slogan: We are social epistemic agents.

\section{References}

Friedman, Michael (1974). "Explanation and Scientific Understanding", Journal of Philosophy 71 (1): 5-19.

Goldman, Alvin (1999). Knowledge in a Social World. Oxford: Oxford University Press.

Hempel, Carl (1966). Philosophy of Natural Science. Englweood Cliffs, NJ: Prentice-Hall.

Ladyman, James, Igor Douven, Leon Horsten, and Bas van Fraassen (1997). "A Defense of van Fraassen's Critique of Abductive Inference: Reply to Psillos", The Philosophical Quarterly 47 (188): 305-321.

Musgrave, Alan (2017). "Strict Empiricism Versus Explanation in Science", In Evandro Agazzi (ed.), Varieties of Scientific Realism: Objectivity and Truth in Science. Switzerland: Springer International Publishing, 71-93.

Papineau, David (1996). The Philosophy of Science. Oxford: Oxford University Press.

Park, Seungbae (2003). "Ontological Order in Scientific Explanation”, Philosophical Papers 32 (2): $157-170$.

(2009). "Philosophical Responses to Underdetermination in Science", Journal for General Philosophy of Science 40: 115-124.

(2014). "On the Relationship between Speech Acts and Psychological States", Pragmatics and Cognition 22 (3): 340-351.

${ }^{11}$ I thank the second anonymous referee for requesting me to explore this issue.

12 Stanford's antirealist explanation is conceptually flawed (Park, 2003: 164-168). 
-------- (2015). “Accepting Our Best Scientific Theories”, Filosofija. Sociologija 26 (3): $218-227$.

(2016). “How to Foster Scientists' Creativity”, Creativity Studies 9 (2): 117-126.

16 (1): $23-37$

(2017a). "Scientific Antirealists Have Set Fire to Their Own Houses", Prolegomena (2017b). "Defense of Epistemic Reciprocalism", Filosofija. Sociologija 28 (1): 5664.

-------- (2017c). “Understanding without Justification and Belief?" Principia: An International Journal of Epistemology 21(3): 379-389.

(2017d). "Does Scientific Progress Consist in Increasing Knowledge or Understanding?", Journal for General Philosophy of Science 48 (4): 569-579.

--------- (2018a). "Philosophers and Scientists are Social Epistemic Agents", Social Epistemology Review and Reply Collective 7 (6): 31-43.

--------- (2018b). "In Defense of the Epistemic Imperative”, Axiomathes 28 (4): 435-446.

-------- (2018c). “The Pessimistic Induction and the Golden Rule”, Problemos 93: 70-80.

17: 7-19.

(2018d). "The Grand Pessimistic Induction", Review of Contemporary Philosophy

(2018e). “The Problem of Unobserved Anomalies”, Filosofija. Sociologija 29 (1):

4-12.

Salmon, Wesley (1971). Statistical Explanation and Statistical Relevance. Pittsburgh: University of Pittsburgh Press.

Seeman, Jeffrey (2018). "From 'Multiple Simultaneous Independent Discoveries' to the Theory of "Multiple Simultaneous Independent Errors": A Conduit in Science", Foundations of Chemistry. https://doi.org/10.1007/s10698-018-9304-0.

Stanford, P. Kyle (2000). "An Antirealist Explanation of the Success of Science", Philosophy of Science 67 (2): 266-284.

van Fraassen, Bas (1980). The Scientific Image. Oxford: Oxford University Press.

(1985). "Empiricism in the Philosophy of Science" In Images of Science. P. Churchland and C. Hooker (eds.), Chicago: University of Chicago Press.

(1989). Laws and Symmetry. Oxford: Oxford University Press. 
(2007). "Reply: From a View of Science to a New Empiricism", In Bradley Monton (ed.), Images of Empiricism: Essays on Science and Stances, with a Reply from Bas van Fraassen. Oxford: Oxford University Press, 337-383.

(2017). "Misdirection and Misconception in the Scientific Realism Debates", In Evandro Agazzi (ed.), Varieties of Scientific Realism: Objectivity and Truth in Science. Switzerland: Springer International Publishing, 95-108.

Wray, K. Brad (2007). "A Selectionist Explanation for the Success and Failures of Science", Erkenntnis 67 (1): 81-89.

(2010). "Selection and Predictive Success", Erkenntnis 72 (3): 365-377. 